\title{
ORIGINAL
}

\section{Adrenocortical function during prolonged critical illness and beyond: a prospective observational study}

\author{
Bram Peeters ${ }^{1}$, Philippe Meersseman ${ }^{1,2}$, Sarah Vander Perre ${ }^{1}$, Pieter J. Wouters ${ }^{1}$, Dimitri Vanmarcke ${ }^{1}$, \\ Yves Debaveye ${ }^{1}$, Jaak Billen ${ }^{3}$, Pieter Vermeersch', Lies Langouche ${ }^{1}$ and Greet Van den Berghe ${ }^{1 *}$ (D)
}

(C) 2018 The Author(s)

\begin{abstract}
Purpose: For patients suffering from prolonged critical illness, it is unknown whether and when the hypothalamuspituitary-adrenal axis alterations recover, and to what extent adrenocortical function parameters relate to sepsis/septic shock, to clinical need for glucocorticoid treatment, and to survival.

Methods: Patients still in ICU on day $7(N=392)$ and 20 matched healthy subjects were included. Morning blood and 24-h urine were collected daily and cosyntropin tests $(250 \mu \mathrm{g})$ performed weekly, repeated 1 week after ICU discharge on the regular ward.

Results: In all patients free of glucocorticoid treatment up until ICU day $28(N=347)$, plasma ACTH always remained low/normal, whereas free cortisol remained high $(P \leq 0.002)$ explained by reduced binding proteins $(P \leq 0.02)$ and suppressed cortisol breakdown ( $P \leq 0.001)$. Beyond ICU day 28 ( $N=64$ long-stayers), plasma (free)cortisol was no longer elevated. One week after ICU discharge, plasma ACTH and (free)cortisol always rose to supra-normal levels $(P \leq 0.006)$, most pronounced in long-stayers. Long-stayers always showed low incremental total $(P \leq 0.001)$, but normal incremental free cortisol responses to weekly cosyntropin tests, explained by low cortisol plasma binding proteins. Sepsis/septic shock patients were not different from others, patients subsequently receiving glucocorticoids $(N=45)$ were not different from those who did not, and non-survivors were distinguishable from survivors only by higher (free)cortisol.

Conclusions: Irrespective of sepsis/septic shock, need for glucocorticoids and survival, low cortisol plasma binding proteins and suppressed cortisol breakdown determine systemic (free)cortisol availability in prolonged critical illness, the latter no longer elevated beyond ICU day 28. The uniform rise in ACTH and cortisol to supra-normal levels 1 week after ICU discharge indicates recovery of a central adrenocortical suppression while in ICU. Low cortisol plasma binding invalidates the cosyntropin test.
\end{abstract}

Keywords: HPA axis, Sepsis, Septic shock, CIRCl, Adrenal insufficiency, Glucocorticoids

${ }^{*}$ Correspondence: greet.vandenberghe@kuleuven.be

${ }^{1}$ Clinical Division and Laboratory of Intensive Care Medicine, Department of Cellular and Molecular Medicine, KU Leuven, Herestraat 49, 3000 Leuven, Belgium

Full author information is available at the end of the article 


\section{Introduction}

High plasma concentrations of total and free cortisol and low levels of cortisol binding proteins hallmark critical illness [1]. Until recently, several-fold increased ACTHdriven cortisol production was considered to be the main driver of critical illness-induced hypercortisolism. However, studies have reported low rather than high plasma ACTH throughout the first week in ICU, a cortisol production rate that was not or only slightly higher than in matched healthy subjects and an important role for suppressed cortisol breakdown in bringing about hypercortisolism in the critically ill [1-3]. Possible explanations for low plasma ACTH comprise feedback inhibition exerted by circulating (free)cortisol that is elevated via nonACTH-dependent secretion and via suppressed breakdown [1], or inflammation- and hypoxia-induced cellular damage to the hypothalamus and/or the pituitary gland $[4,5]$. Also, the integrity of the adrenal cortex could be impaired by hypoxia, inflammation, or hemorrhage causing primary adrenal insufficiency or by sustained reduced ACTH signaling, evoking central hypoadrenalism [6]. It is currently unknown whether and when these alterations in ACTH and cortisol recover in critically ill patients suffering from various diseases including sepsis/septic shock.

Experts have defined "critical illness-related corticosteroid insufficiency" (CIRCI) as the condition in which patients may not, or may no longer, be able to produce the required amount of cortisol that is essential for survival [7]. Patients suffering from septic shock and longstay ICU patients are assumed to be particularly at risk of developing CIRCI [8-11]. Experts have advised to diagnose CIRCI either by an incremental cortisol response to $250 \mu \mathrm{g}$ of cosyntropin $\left(\right.$ Synacthen ${ }^{\circledR}$ ) below $9 \mu \mathrm{g} / \mathrm{dl}$ or by a random plasma total cortisol below $10 \mu \mathrm{g} / \mathrm{dl}[12,13]$. However, the concept of CIRCI as a clinical entity that should be treated remains controversial. Indeed, it is not known how many patients would fulfill these presumed criteria of CIRCI without any obvious clinical need for glucocorticoid treatment. Vice versa, it has not been investigated whether initiation of glucocorticoid treatment in the ICU is supported by abnormalities in adrenocortical function parameters.

We here investigated whether and when the central and peripheral alterations that occur within the hypothalamus-pituitary-adrenal axis during prolonged critical illness recover, and to what extent the currently used diagnostic criteria for CIRCI relate to septic shock, need for glucocorticoid treatment, and survival. To this end, we documented the changes over time-from ICU day 7 up to recovery or death-in plasma ACTH and (free) cortisol, urinary cortisol metabolites, and in plasma total

\section{Take-home message}

First, unlike what is generally assumed, not the presence of septic shock, but rather an extended duration of ICU stay beyond 4 weeks explains lack of elevated free cortisol that is not compensated by increased ACTH, which could be due to a central (endogenous or exogenous) adrenocortical suppression. Second, cosyntropin stimulation tests, currently advised for the diagnosis of critical illness-related corticosteroid insufficiency (CIRCI), are confounded by increased cortisol distribution volume-which lowers the incremental total but not free cortisol responses to cosyntropinand thus these tests cannot provide reliable information on the adrenocortical integrity or functional reserve.

and free cortisol responses to cosyntropin, with focus on long-stay ( $\geq 4$ weeks in ICU) patients in comparison with shorter-stay patients (1-2 weeks; $2-3$ weeks; $3-4$ weeks in ICU).

Some of the results of this study were previously reported in the form of an abstract [14].

\section{Methods}

\section{Study design, study participants, and sample size} calculation

This prospective observational study was performed in five medical/surgical ICUs at the University Hospitals of Leuven, Belgium. Consecutive adult (age $\geq 18$ years) critically ill patients were screened for eligibility on ICU day 6. Exclusion criteria were (details provided in the Supplementary Material) treatment with systemic glucocorticoids, etomidate, azoles, or other drugs predisposing to adrenal insufficiency, no vital organ support, no arterial or central venous catheter in place, referral from another ICU, cerebral/pituitary/adrenal disorders with impact on the neuroendocrine system, enrollment in another trial, or expected death within $12 \mathrm{~h}$. On ICU day 7, after written informed consent from the patient or next of kin, the study started.

The required study sample size was determined by an estimated effect size of longer duration of critical illness on adrenocortical function and plasma ACTH. To detect primary adrenal insufficiency occurring within 4 weeks in ICU (causing plasma ACTH $>50 \%$ above healthy values), with $80 \%$ power and $95 \%$ certainty, 64 patients-not receiving glucocorticoid treatment up to ICU day 28and 20 healthy controls matched for age, gender, and BMI were needed (Table 1) [1]. Also, within this time window, this sample size would allow us to detect an adaptive stress response, with pituitary reactivation as a result of normalized cortisol breakdown, and thereby a normalization of plasma ACTH in patients who recover. Recruitment started on February 18, 2015 and continued until 64 patients fulfilled the requirements of ICU stay $\geq 4$ weeks (ICU $\geq 4 \mathrm{w}$ ) without receiving glucocorticoids (July 7 , 
Table 1 Participant characteristics

\begin{tabular}{|c|c|c|c|c|c|c|c|}
\hline & $\begin{array}{l}\text { Healthy subjects } \\
(n=20)\end{array}$ & $P$ value* & $\begin{array}{l}\text { ICU stay } 1-2 \mathrm{w} \\
(n=164)\end{array}$ & $\begin{array}{l}\text { ICU stay } 2-3 w \\
(n=75)\end{array}$ & $\begin{array}{l}\text { ICU stay } 3-4 w \\
(n=44)\end{array}$ & $\begin{array}{l}\text { ICU stay } \geq 4 w \\
(n=64)\end{array}$ & $P$ value ${ }^{* *}$ \\
\hline \multicolumn{8}{|l|}{ Demography and anthropometry } \\
\hline Male gender, no. (\%) & $14(70)$ & 0.83 & $108(66)$ & $51(68)$ & $29(66)$ & $47(73)$ & 0.73 \\
\hline Age, year (mean \pm SEM) & $64 \pm 2$ & 0.87 & $64 \pm 1$ & $64 \pm 2$ & $59 \pm 2$ & $65 \pm 2$ & 0.18 \\
\hline $\mathrm{BMI}^{\mathrm{a}}, \mathrm{kg} / \mathrm{m}^{2}$ (mean $\left.\pm \mathrm{SEM}\right)$ & $26.4 \pm 0.7$ & 0.82 & $26.4 \pm 0.4$ & $26.1 \pm 0.5$ & $26.4 \pm 0.8$ & $26.9 \pm 0.8$ & 0.88 \\
\hline \multicolumn{8}{|l|}{ Admission characteristics } \\
\hline Diabetes mellitus, no. (\%) & & & $22(13)$ & $20(27)$ & $7(16)$ & $11(17)$ & 0.17 \\
\hline Malignancy, no. (\%) & & & $26(16)$ & $7(9)$ & $3(7)$ & $10(16)$ & 0.44 \\
\hline APACHE II score ${ }^{b}$ (mean \pm SEM) & & & $28 \pm 1$ & $29 \pm 1$ & $31 \pm 1$ & $31 \pm 1$ & 0.02 \\
\hline Emergency admission, no. (\%) & & & $128(78)$ & $58(77)$ & $34(77)$ & $53(83)$ & 0.84 \\
\hline Diagnostic admission categories & & & & & & & 0.001 \\
\hline Cardiac surgery, no. (\%) & & & $29(18)$ & $21(28)$ & $13(29)$ & $13(20)$ & \\
\hline Complicated other surgery, no. (\%) & & & $63(38)$ & $17(23)$ & $11(25)$ & $27(42)$ & \\
\hline Multiple trauma and burns, no. (\%) & & & $11(7)$ & $12(16)$ & $6(14)$ & $14(22)$ & \\
\hline Medical, no. (\%) & & & $61(37)$ & $25(33)$ & $14(32)$ & $10(16)$ & \\
\hline \multicolumn{8}{|c|}{ Patient characteristics at study inclusion (ICU day 7) } \\
\hline Infection, no. (\%) & & & $123(75)$ & $62(83)$ & $40(91)$ & $53(83)$ & 0.08 \\
\hline Sepsis ${ }^{c}$, no. (\%) & & & $103(63)$ & $57(76)$ & $38(86)$ & $47(73)$ & 0.009 \\
\hline Septic shock ${ }^{c}$, no. (\%) & & & $45(27)$ & $34(45)$ & $21(47)$ & $38(59)$ & $<0.0001$ \\
\hline $\begin{array}{l}\text { Requiring vasopressors on ICU day } \\
7, \text { no. (\%) }\end{array}$ & & & $67(41)$ & $41(55)$ & $24(55)$ & $50(78)$ & $<0.0001$ \\
\hline $\begin{array}{l}\text { Norepinephrine infusion rate } \\
\text { on ICU day } 7, \mu \mathrm{g} / \mathrm{kg} / \mathrm{min} \\
\text { (mean } \pm \mathrm{SEM} \text { ) }\end{array}$ & & & $0.03 \pm 0.01$ & $0.04 \pm 0.01$ & $0.06 \pm 0.02$ & $0.09 \pm 0.01$ & $<0.0001$ \\
\hline $\begin{array}{l}\text { Treatment with inhaled glucocorti- } \\
\text { coids on ICU day } 7, \text { no. (\%) }\end{array}$ & & & $8(5)$ & $1(1)$ & $1(2)$ & $1(2)$ & 0.38 \\
\hline \multicolumn{8}{|l|}{ Clinical outcomes } \\
\hline Days in ICU (mean \pm SEM) & & & $10 \pm 0$ & $17 \pm 0$ & $23 \pm 0$ & $49 \pm 3$ & $<0.0001$ \\
\hline ICU non-survivor, no. (\%) & & & $20(12)$ & $8(11)$ & $6(14)$ & $13(20)$ & 0.34 \\
\hline
\end{tabular}

ICU intensive care unit

*The comparison between healthy subjects and all patients

**The comparison between patient groups

a Body mass index (BMI) is the weight in kilograms divided by the square of the height in meters

b Acute Physiology and Chronic Health Evaluation II (APACHE II) score reflects severity of illness, with higher values indicating more severe illness, and can range from 0 to $71[28]$

c Incidence of sepsis and septic shock was defined according to [29, 30]

2017) (Fig. S1). Patients who were discharged or died before this time point were analyzed for comparison, divided into three groups based on duration of ICU stay [between 1 and 2 weeks (ICU1-2w), between 2 and 3 weeks (ICU2-3w), between 3 and 4 weeks (ICU3$4 \mathrm{w})$ ]. The day of ICU discharge was defined as the day on which patients no longer required vital organ support. Patients who received glucocorticoids after study inclusion were compared in terms of their last pre-treatment assessment with patients not receiving glucocorticoid treatment, selected pairwise, matched for day of assessment and baseline risks (Table S1).
The study protocol was in accordance to the 1964 Declaration of Helsinki and its later amendments, was approved by the Institutional Ethical Review Board (S57249) and made available prior to study start (ISRCTN98806770).

\section{Clinical data and sample collection}

Demographic, anthropometric, ICU admission characteristics, patient characteristics at study inclusion on ICU day 7, and outcomes were documented (Table 1 and Table S1). From ICU day 7 until ICU day 28 and/or ICU discharge or death, morning blood and 24-h urine samples were collected daily (for details, see Supplementary 
Material). Thereafter, for $\mathrm{ICU} \geq 4 \mathrm{w}$, samples were collected weekly until ICU discharge or death, with an additional sample on the last ICU day. For all patients, a short ACTH-stimulation test [intravenous injection of $250 \mu \mathrm{g}$ cosyntropin (Synacthen ${ }^{\circledR}$ ) with blood sampling before, 30 and $60 \mathrm{~min}$ after injection] was performed weekly. Seven days after ICU discharge, an additional blood sample was taken and a cosyntropin test was performed on the ward. For the demographically matched healthy volunteers, morning blood and 24-h urine were sampled and a cosyntropin test was performed. Details on sampling procedure and sample storing are provided in the Supplementary Material.

\section{Quantification of plasma ACTH and (free)cortisol concentrations}

Plasma ACTH concentrations were measured with a double-monoclonal immunoradiometric assay (Brahms Diagnostics) and cortisol (Immunotech) and cortisol-binding-globulin (CBG) (Riazen) were measured by competitive radioimmunoassay. Plasma albumin was quantified by the bromocresol green colorimetric method (Sigma-Aldrich). Plasma free cortisol was calculated using the Coolens formula adapted for individual albumin and CBG concentrations, previously validated as representative of measured free cortisol in the ICU context $[15,16]$. Results were not available to the bedside clinicians.

\section{Estimation of the activity of cortisol metabolizing enzymes} Liquid chromatography-tandem mass spectrometry (LC-MS/MS) was used to determine absolute urinary concentrations of cortisol (F), $5 \alpha$-tetrahydrocortisol (allo-THF), $5 \beta$-tetrahydrocortisol (THF), cortisone (E), $5 \alpha$-tetrahydrocortisone (allo-THE), and tetrahydrocortisone (THE) after deglucuronidation. The activity of $11 \beta-H S D 2$ was estimated by the E/F ratio, activity of $5 \alpha$-reductase by allo-THF/F and allo-THE/E ratios, and activity of $5 \beta$-reductase by THF/F and THE/E ratios. These estimations were performed only for $\mathrm{ICU} \geq 4 \mathrm{w}$ patients weekly throughout the ICU stay. Results were not available to bedside clinicians.

\section{Statistical analyses}

Data are presented as mean \pm standard errors (SEM) or numbers and percentages, as appropriate. Continuous data were compared with unpaired Student's $t$ tests, where necessary after transformation to obtain a nearnormal distribution. Proportions were compared with the use of chi-square tests. Time series were compared with repeated-measures ANOVA, where necessary after transformation to obtain a near-normal distribution. Statistical analyses were performed with JMP ${ }^{\circledR}$ Pro (v13.0.0,
SAS Institute). Two-sided $P$ values $\leq 0.05$ were considered to indicate statistical significance. No corrections for multiple comparisons were done.

\section{Results \\ Patient characteristics}

A total of 392 patients were included in the study and 45 subsequently received glucocorticoids (Fig. S1). Of the remaining 347 included patients, 64 patients fulfilled the requirements of being critically ill for $\geq 4$ weeks. The 283 patients who were discharged from ICU or died before day 28 were divided into three groups for duration of ICU stay (1-2 weeks; 2-3 weeks; $3-4$ weeks) (Table 1 ). Patients who subsequently received glucocorticoids were comparable to those who did not, with the exception of a higher admission APACHE II score, higher proportions of patients with sepsis and septic shock, a longer ICU stay, and higher mortality (Table S1).

Results for the 347 patients who did not receive treatment with glucocorticoids

Changes in plasma ACTH and cortisol concentrations over time in ICU and on the regular ward

As compared with healthy subjects, plasma ACTH concentrations were low/normal and plasma total and free cortisol concentrations were high for all patients on ICU day 7 (Fig. 1a1-a3), with a trend for lower ACTH $(P=0.09)$ and significantly higher free cortisol $(P=0.002)$ for ICU $\geq 4 \mathrm{w}$ patients than for shorter-stayers. There was no effect of treatment with inhaled glucocorticoids on plasma ACTH $(P=0.53)$, on total $(P=0.51)$ and free $(P=0.77)$ cortisol on ICU day 7 . The suppressed ACTH gradually normalized towards ICU discharge, whereas free cortisol progressively decreased but remained higher than normal, except for $I C U \geq 4 \mathrm{w}$ patients (Fig. 1a1-a3). On ICU day 7, plasma CBG (Fig. 1a4) concentrations in all patients were lower than in healthy subjects. CBG gradually increased to healthy reference values towards ICU discharge, but stayed lower than normal, in particular for ICU $\geq 4 \mathrm{w}$ patients (Fig. 1a4). Plasma albumin concentrations were always low $(4.1 \pm 0.02 \mathrm{~g} / \mathrm{dl}$ versus $7.8 \pm 0.2 \mathrm{~g} / \mathrm{dl}, P<0.0001$ ).

As compared with the last value obtained in ICU, 1 week after ICU discharge, all surviving patients revealed a $66 \%$ increase in plasma $\mathrm{ACTH}$, a $22 \%$ rise in plasma total cortisol, a $29 \%$ increase in plasma free cortisol, a $4 \%$ increase in plasma CBG, and a $9 \%$ increase in plasma albumin $(P<0.0001)$ (Fig. 1b). Remarkably, for $\mathrm{ICU} \geq 4 \mathrm{w}$ patients, as compared with shorter-stayers, the rise in plasma free cortisol was larger $(P=0.02)$ and tended to be larger for total cortisol $(P=0.06)$. For all patients tested 7 days post-ICU on the regular ward, plasma ACTH and plasma (free)cortisol concentrations 


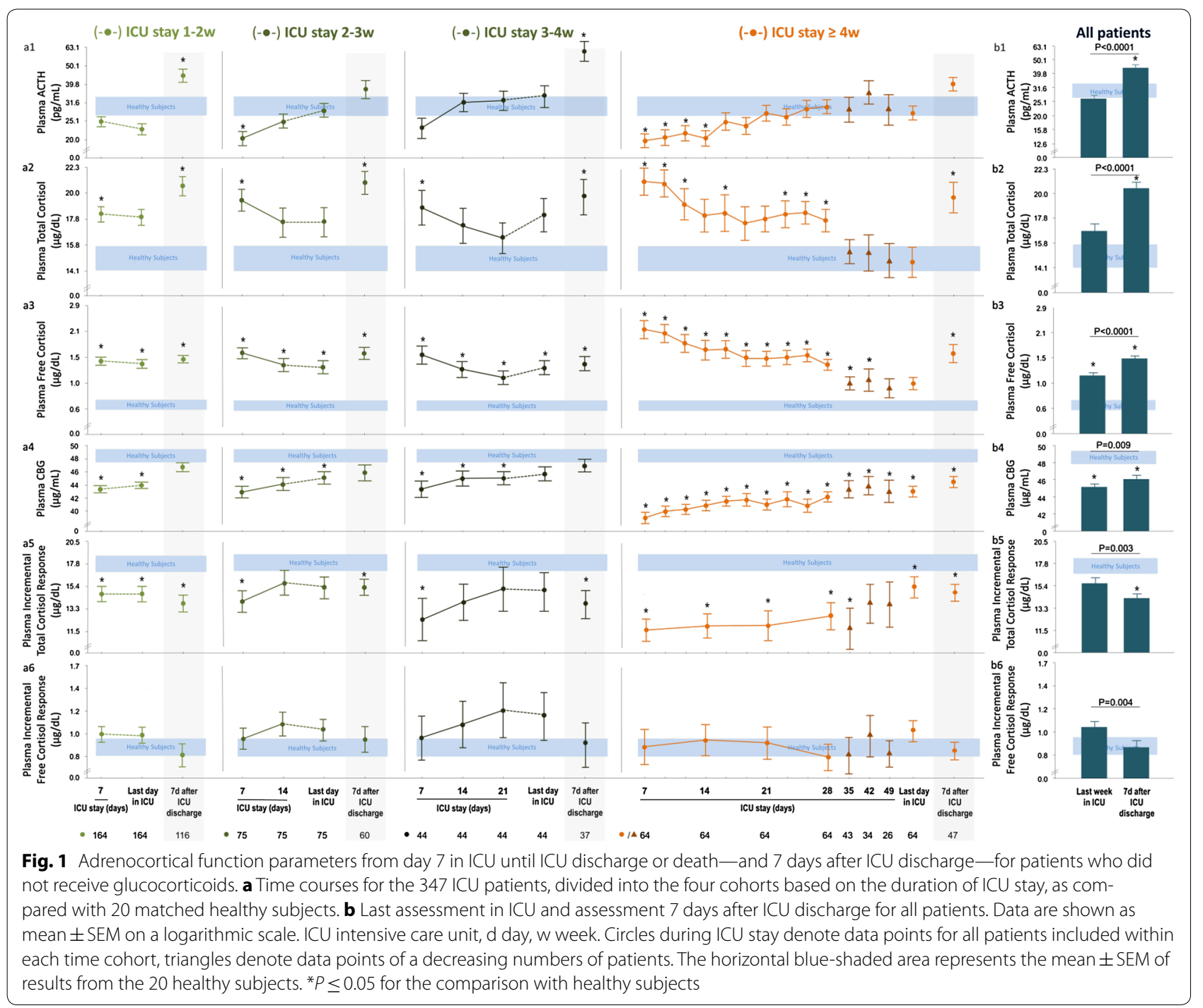

were higher than those of healthy subjects (Fig. 1b1b3), whereas plasma CBG (Fig. 1b4) and albumin $(4.8 \pm 0.08 \mathrm{~g} / \mathrm{dl}$ versus $7.8 \pm 0.2 \mathrm{~g} / \mathrm{dl} ; \mathrm{P}<0.0001)$ concentrations were still lower.

\section{Changes in incremental cortisol responses to cosyntropin over time in ICU and on the regular ward}

Incremental total cortisol responses to cosyntropin were either normal or low for shorter-stayers, whereas ICU $\geq 4 \mathrm{w}$ patients uniformly revealed suppressed incremental total cortisol responses throughout the ICU stay (Fig. 1a5). In contrast, incremental free cortisol responses were always normal in all patients at all times (Fig. 1a6). Incremental total cortisol responses correlated positively with plasma CBG concentrations $(P<0.0001)$. There was no effect of treatment with inhaled glucocorticoids on incremental total $(P=0.48)$ and free $(P=0.85)$ cortisol responses on ICU day 7. As compared with the last value obtained in ICU, 1 week post-ICU, all surviving patients revealed a $9 \%$ decrease in incremental total cortisol response, and a $17 \%$ decrease in incremental free cortisol response (Fig. 1b5-b6). Incremental total cortisol responses to cosyntropin measured 1 week post-ICU were lower than those of healthy subjects, and incremental free cortisol responses were normal (Fig. 1b5-b6).

\section{Changes in estimated activity of cortisol-metabolizing enzymes over time during ICU stay}

For ICU $\geq 4 \mathrm{w}$ patients, estimated activities of $11 \beta-H S D 2$, $5 \alpha$-reductase, and $5 \beta$-reductase were lower than in healthy subjects at all times (Fig. 2). From ICU day 7 to the last ICU day, the estimated activity of $11 \beta-$ HSD 2 and 


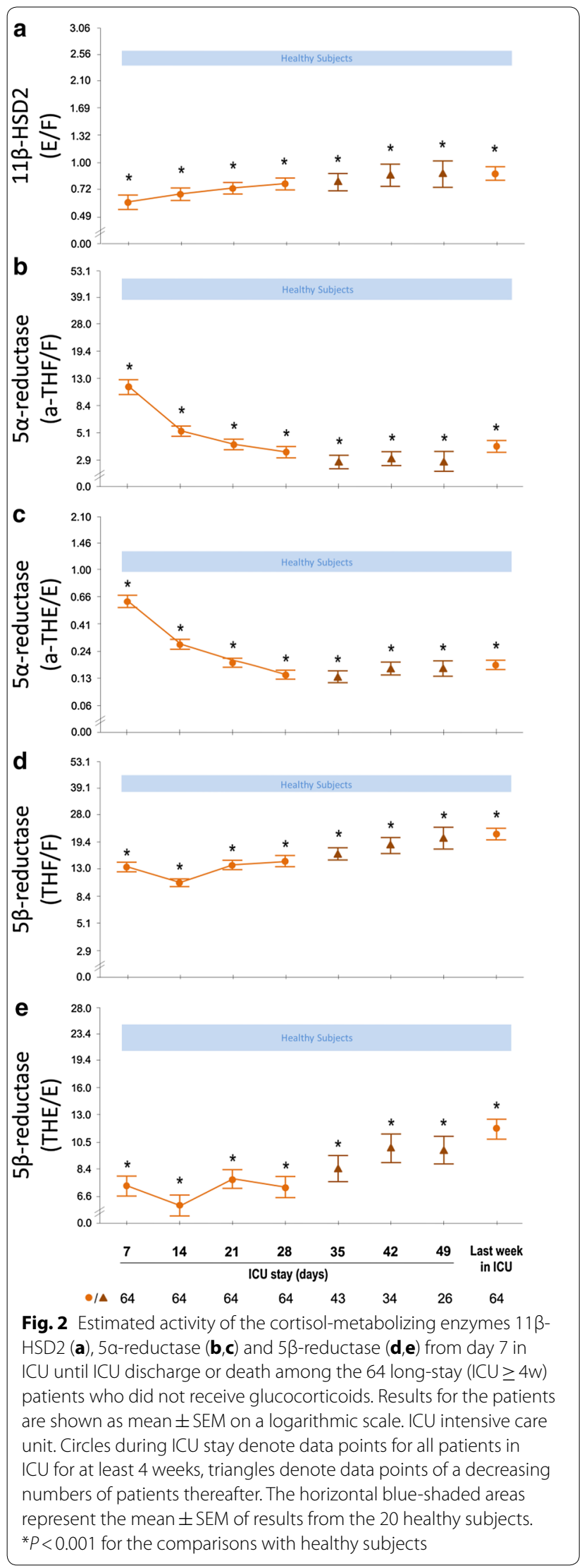

of $5 \beta$-reductase slightly increased $(P \leq 0.0001)$ but always remained lower than normal, whereas the estimated activity of $5 \alpha$-reductase further decreased $(P<0.0001)$.

\section{Comparison of ICU $\geq 4$ w patients with and without sepsis/ septic shock}

As compared with patients not suffering from sepsis, patients with sepsis revealed similar plasma ACTH, total and free cortisol, CBG and albumin concentrations (Fig. 3a1-a6). A random plasma cortisol $<10 \mu \mathrm{g} / \mathrm{dl}$ at any time in ICU occurred in $30 \%$ of patients with sepsis and in $35 \%$ of patients without sepsis $(P=0.67)$. An incremental total cortisol response to cosyntropin $<9 \mu \mathrm{g} / \mathrm{dl}$ at any time in ICU occurred in $59 \%$ of the patients with sepsis and in $41 \%$ of patients without sepsis $(P=0.19)$.

Similar results were obtained for the comparison of patients with and without septic shock (Fig. 3b1-b6). A random plasma cortisol $<10 \mu \mathrm{g} / \mathrm{dl}$ at any time in ICU occurred in $32 \%$ of patients with septic shock versus $31 \%$ of patients without septic shock $(P=0.94)$. An incremental total cortisol response to cosyntropin $<9 \mu \mathrm{g} / \mathrm{dl}$ at any time in ICU occurred in $61 \%$ of patients with septic shock versus $46 \%$ of patients without septic shock $(P=0.25)$. Also, patients with septic shock were not different from patients with sepsis without shock (data not shown).

\section{Comparison of $I C U \geq 4 w$ survivors with $I C U \geq 4 w$ non-survivors}

Plasma free and total cortisol concentrations were always higher or tended to be higher in non-survivors than in survivors, in the face of comparable plasma ACTH (Fig. 3c1-c3). Plasma CBG concentrations were always lower in non-survivors than in survivors, whereas albu$\min (P=0.15)$ and the incremental total and free cortisol responses to cosyntropin were similar (Fig. 3c4). A random plasma cortisol $<10 \mu \mathrm{g} / \mathrm{dl}$ at any time in $\mathrm{ICU}$ occurred in $35 \%$ of survivors and in $15 \%$ of non-survivors $(P=0.16)$. An incremental total cortisol response to cosyntropin $<9 \mu \mathrm{g} / \mathrm{dl}$ at any time in ICU occurred in $53 \%$ of survivors and in $62 \%$ of non-survivors $(P=0.57)$.

\section{Comparison of patients who subsequently received glucocorticoid treatment with those who did not}

Of the 45 patients who were included on ICU day 7 and who subsequently received glucocorticoids, 24 could be matched to 24 patients who were not treated with glucocorticoids, for comparison of adrenocortical function parameters on the same ICU day (ICU day 14 \pm 1 ). None of the studied adrenocortical function parameters in these patients who received glucocorticoid treatment differed from those who were not treated (Fig. 4). This was also the case when only considering hydrocortisone-treated patients (data not shown). Furthermore, 

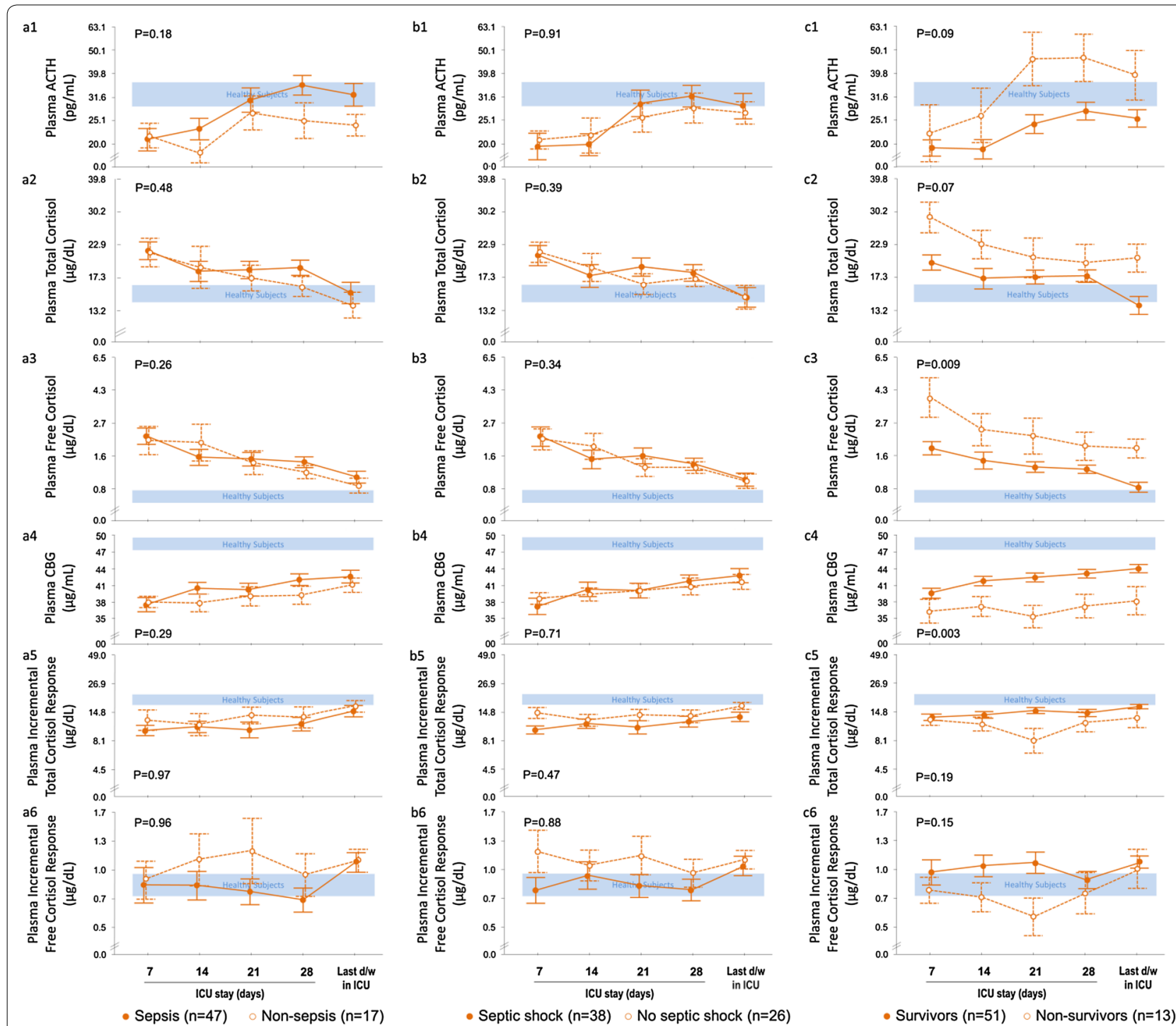

Fig. 3 Adrenocortical function parameters from day 7 in ICU until ICU discharge or death in long-stay (ICU $\geq 4$ w) patients who did not receive glucocorticoids, a compared for the presence or absence of sepsis, $\mathbf{b}$ compared for the presence or absence of septic shock, and $\mathbf{c}$ compared for survivors and non-survivors. Data are shown as mean \pm SEM on a logarithmic scale. ICU intensive care unit. The horizontal blue-shaded areas represent the mean \pm SEM of results from the 20 healthy subjects. The numerical $P$ values are those for the comparisons between patient groups

a random plasma cortisol $<10 \mu \mathrm{g} / \mathrm{dl}$ occurred in $13 \%$ of both glucocorticoid-treated patients on the pre-treatment day and of matched patients who did not receive glucocorticoid treatment $(P>0.90)$. An incremental total cortisol response to cosyntropin $<9 \mu \mathrm{g} / \mathrm{dl}$ occurred in $43 \%$ of glucocorticoid-treated patients versus $40 \%$ of glucocorticoid-untreated patients $(P=0.81)$.

\section{Discussion}

In this prospective study of prolonged critically ill patients requiring $>7$ days of intensive care, plasma $\mathrm{ACTH}$ remained low/normal throughout ICU stay up to day 28 , whereas plasma free cortisol remained high, largely explained by low plasma binding and persistently suppressed cortisol breakdown, irrespective of the presence of sepsis/septic shock. In particular the low binding proteins among sicker patients and non-survivors determined their higher plasma free cortisol levels. Development of primary adrenal failure was not observed. However, beyond ICU day 28, plasma free cortisol was no longer elevated and not compensated by increased $\mathrm{ACTH}$, which could be due to a central (endogenous or exogenous) adrenocortical suppression. Such a central suppression was further supported by the uniform rise in 

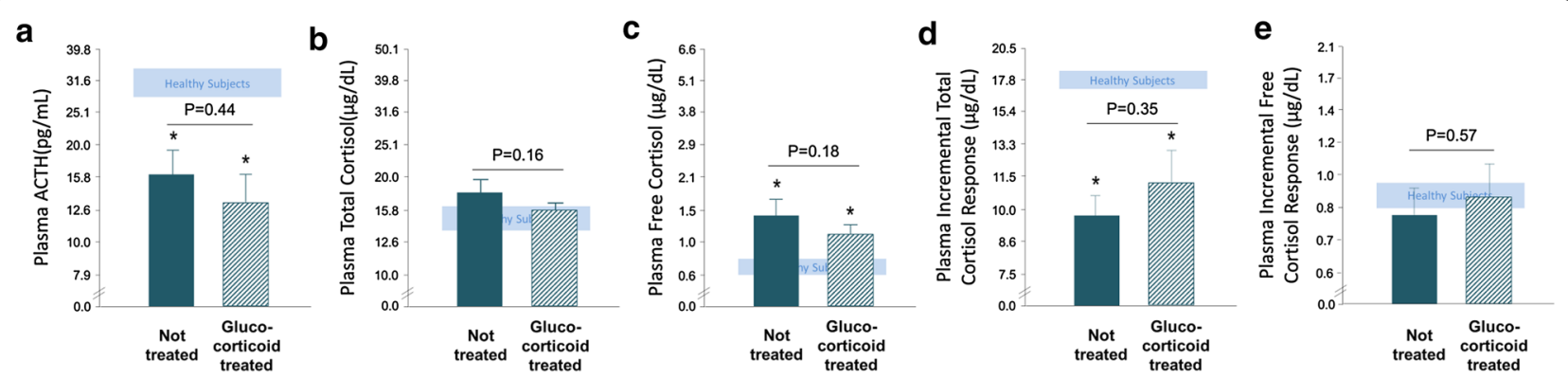

Fig. 4 Adrenocortical function parameters for patients on the last pre-glucocorticoid treatment assessment and for patients who did not receive glucocorticoids, matched for risk factors and day of assessment. a plasma ACTH, b total cortisol, c free cortisol, d incremental total cortisol response, $\mathbf{e}$ incremental free cortisol response. Data are shown as mean \pm SEM on a logarithmic scale. The horizontal blue-shaded areas represent the mean \pm SEM of results from the 20 healthy subjects. The numerical $P$ values are those for the comparisons between patient groups and ${ }^{*} P \leq 0.01$ for the comparisons with healthy subjects

plasma ACTH and (free)cortisol to supra-normal levels 1 week later on the regular ward. Low incremental total cortisol responses to cosyntropin coincided with normal free cortisol responses at all times. Hence, low responses to cosyntropin during critical illness likely reflected the increased cortisol distribution volume, which has been documented in an earlier study [1], given low plasma binding, rather than the functional reserve of the adrenal cortex. Finally, the initiation of glucocorticoid treatment, as judged necessary by bedside clinicians, was not supported by differences in the presently measured adrenal function parameters.

A first important finding was a plasma ACTH that was never elevated and mostly low throughout ICU stay, whereas plasma (free)cortisol remained higher than normal, and that cortisol breakdown always remained suppressed. However, with illness persisting beyond 4 weeks, plasma (free)cortisol gradually decreased to healthy reference values, which was not accompanied by elevated plasma ACTH. This is unexpected given the high severity of illness. The observation of a clear increase in plasma $\mathrm{ACTH}$, and in (free)cortisol, 7 days later on the regular ward was striking. Indeed, at that time point, patients were recovering, which would be considered to reduce the need for high systemic cortisol availability. Instead this need appeared to be increased. Together, these findings could suggest a central suppression of ACTH-driven cortisol production in the ICU, most pronounced during the protracted phase of critical illness, which recovered after ICU discharge. One can only speculate on the underlying mechanism of such a suppression which could be of endogenous or exogenous origin. A protracted central suppression would explain the previously observed adrenal atrophy in long-stay, but not short-stay ICU patients, documented post-mortem $[11,17,18]$. The rise in systemic cortisol availability after ICU discharge could suggest that the systemic cortisol availability during critical illness may not be sufficient for the level of stress. Although this could suggest a form of CIRCI, the diagnosis with use of advised tests is troublesome. Indeed, in this study, neither a total plasma cortisol $<10 \mu \mathrm{g} / \mathrm{dl}$ nor an incremental cortisol response to cosyntropin $<9 \mu \mathrm{g} / \mathrm{dl}$ identified patients with shock or at risk of death.

Indeed, all long-stay ICU patients alike revealed low total cortisol responses to cosyntropin throughout ICU stay, a finding that can be explained by the very low plasma CBG concentrations that increase cortisol distribution volume. Such an explanation is supported by the much lower than normal peak total plasma cortisol concentration in response to a bolus injection of $100 \mathrm{mg}$ hydrocortisone previously observed for ICU patients, with a calculated distribution volume that was $\pm 40 \%$ higher than normal [1]. Hence, the low incremental total plasma cortisol response to cosyntropin in the critically ill could be compatible with a normal amount of cortisol released from the adrenal cortex, diluted over an increased distribution volume. This possibility is further supported by the normal to high incremental free cortisol responses. It therefore seems unlikely that an incremental total cortisol response to cosyntropin of $<9 \mu \mathrm{g} / \mathrm{dl}$ adequately points to the presence of CIRCI.

Surprisingly, those patients for whom clinicians at the bedside decided it was appropriate to treat with glucocorticoids could not be distinguished on the basis of the studied adrenal function parameters from patients who did not need such treatment, after careful matching for type, severity, and duration of illness. Instead, this finding suggests that glucocorticoids are often given to patients with the aim to increase blood pressure or to reduce inflammation [19-26]. Whether these are justified indications remains debated $[12,13]$. The most recent randomized controlled trials (RCTs) investigating glucocorticoid treatment for septic shock showed opposite results, adding to the ongoing controversy $[25,26]$. 
A limitation of the study is the use of single morning samples which may have precluded the detection of subtle changes within the dynamics of ACTH and cortisol secretion. However, an earlier study reported that a single morning sample correlated well with secretion as derived by deconvolution analysis of repeated sampling time series [15]. Second, we could not calculate cortisol distribution volume, and therefore relied on previous work [1]. Third, the integrity of the adrenal cortex may have been positively affected by the weekly cosyntropin injections [27]. Fourth, the number of patients requiring intensive care beyond day 28 was relatively small. The strengths of the current study are its large sample size and the longitudinal design, with adrenal function parameters documented repeatedly, up to recovery or death, for patients suffering from various diseases, not only from sepsis/septic shock. This allowed us to conclude that not the presence of vasopressor-treated septic shock but rather the increased cortisol distribution volume, as previously documented in a similar patient population [1], appeared to explain the low incremental total cortisol responses to cosyntropin, which questions the value of this test to assess the integrity of the adrenal cortex. It also reported, for the first time, on the recovery of the changes beyond ICU discharge, which allowed us to hypothesize that long-stay patients in particular may be at risk of insufficient cortisol availability. This hypothesis requires further investigation via an RCT that assesses the effect on patient-centered outcomes either of a lower dose of hydrocortisone among long-stay patients, given the persistently low cortisol breakdown, or of treatment with cosyntropin $[1,27]$.

In conclusion, irrespective of sepsis/septic shock, of clinical need for glucocorticoids, and of survival, low cortisol plasma binding proteins and suppressed cortisol breakdown determine the systemic cortisol availability in prolonged critical illness which is no longer elevated beyond ICU day 28. The uniform rise in ACTH and cortisol to supra-normal levels 1 week after ICU discharge, most pronounced among very long-stayers, indicates recovery of a central adrenocortical suppression while in ICU. Low cortisol plasma binding invalidates the cosyntropin test to investigate adrenocortical functional reserve in the ICU context.

\section{Electronic supplementary material}

The online version of this article (https://doi.org/10.1007/s00134-018-5366-7) contains supplementary material, which is available to authorized users.

\section{Author details}

${ }^{1}$ Clinical Division and Laboratory of Intensive Care Medicine, Department of Cellular and Molecular Medicine, KU Leuven, Herestraat 49, 3000 Leuven, Belgium. ${ }^{2}$ Medical Intensive Care Unit, Department of General Internal Medicine, UZ Leuven, Leuven, Belgium. ${ }^{3}$ Department of Laboratory Medicine, UZ Leuven, Leuven, Belgium.

\section{Acknowledgements}

We thank the patients and healthy volunteers for participating, the clinical staff for excellent protocol compliance, and the research assistants for sample handling and data entry. This work was supported by the Research Foundation-Flanders (FWO) [Grant G091918N to GVdB, research mandate 11 W9315N to BP and $1842019 \mathrm{~N}$ to PV]; by the Methusalem Program of the Flemish Government [METH/14/06 to GVdB and LL via KU Leuven]; by a European Research Council Advanced Grant [AdvG-2017-785809 to GVdB] from European Union's Horizon 2020 research and innovation programme.

\section{Compliance with ethical standards}

\section{Conflicts of interest}

The authors declare that they have no conflict of interest.

\section{Open Access}

This article is distributed under the terms of the Creative Commons Attribution-NonCommercial 4.0 International License (http://creativecommons.org/ licenses/by-nc/4.0/), which permits any noncommercial use, distribution, and reproduction in any medium, provided you give appropriate credit to the original author(s) and the source, provide a link to the Creative Commons license, and indicate if changes were made.

Received: 26 July 2018 Accepted: 5 September 2018

Published online: 13 September 2018

\section{References}

1. Boonen E, Vervenne $H$, Meersseman P, Andrew R, Mortier L, Declercq PE, Vanwijngaerden YM, Spriet I, Wouters PJ, Vander PS, Langouche L, Vanhorebeek I, Walker BR, Van den Berghe G (2013) Reduced cortisol metabolism during critical illness. N Engl J Med 368:1477-1488

2. Vermes I, Beishuizen A, Hampsink RM, Haanen C (1995) Dissociation of plasma adrenocorticotropin and cortisol levels in critically ill patients: possible role of endothelin and atrial natriuretic hormone. J Clin Endocrinol Metab 80:1238-1242

3. Peeters B, Guiza F, Boonen E, Meersseman P, Langouche L, Van den Berghe G (2017) Drug-induced HPA axis alterations during acute critical illness: a multivariable association study. Clin Endocrinol (Oxf) 86:26-36

4. Polito A, Sonneville R, Guidoux C, Barrett L, Viltart O, Mattot V, Siami S, de la Grandmaison GL, Chretien F, Singer M, Gray F, Annane D, Brouland JP, Sharshar T (2011) Changes in CRH and ACTH synthesis during experimental and human septic shock. PLoS One 6:e25905

5. Bornstein SR (2009) Predisposing factors for adrenal insufficiency. N Engl 」 Med 360:2328-2339

6. Boonen E, Bornstein SR, Van den Berghe G (2015) New insights into the controversy of adrenal function during critical illness. Lancet Diabetes Endocrinol 3:805-815

7. Annane D, Pastores SM, Arlt W, Balk RA, Beishuizen A, Briegel J, Carcillo J, Christ-Crain M, Cooper MS, Marik PE, Meduri GU, Olsen KM, Rochwerg B, Rodgers SC, Russell JA, Van den Berghe G (2017) Critical illness-related corticosteroid insufficiency (CIRCI): a narrative review from a Multispecialty Task Force of the Society of Critical Care Medicine (SCCM) and the European Society of Intensive Care Medicine (ESICM). Intensive Care Med 43:1781-1792

8. Annane D, Sebille V, Troche G, Raphael JC, Gajdos P, Bellissant E (2000) A 3-level prognostic classification in septic shock based on cortisol levels and cortisol response to corticotropin. JAMA 283:1038-1045

9. Barquist $E$, Kirton $O$ (1997) Adrenal insufficiency in the surgical intensive care unit patient. J Trauma 42:27-31

10. Van den Berghe $G$ (2016) On the neuroendocrinopathy of critical illness. Perspectives for feeding and novel treatments. Am J Respir Crit Care Med 194:1337-1348

11. Peeters B, Langouche L, Van den Berghe G (2017) Adrenocortical stress response during the course of critical illness. Compr Physiol 8:283-298

12. Annane D, Pastores SM, Rochwerg B, Arlt W, Balk RA, Beishuizen A, Briegel J, Carcillo J, Christ-Crain M, Cooper MS, Marik PE, Umberto Meduri G, Olsen KM, Rodgers S, Russell JA, Van den Berghe G (2017) Guidelines for 
the diagnosis and management of critical illness-related corticosteroid insufficiency (CIRCI) in critically ill patients (part I): Society of Critical Care Medicine (SCCM) and European Society of Intensive Care Medicine (ESICM) 2017. Intensive Care Med 43:1751-1763

13. Annane D, Pastores SM, Rochwerg B, Arlt W, Balk RA, Beishuizen A, Briegel J, Carcillo J, Christ-Crain M, Cooper MS, Marik PE, Umberto Meduri G, Olsen KM, Rodgers SC, Russell JA, Van den Berghe G (2017) Guidelines for the diagnosis and management of critical illness-related corticosteroid insufficiency (CIRCI) in critically ill patients (part I): Society of Critical Care Medicine (SCCM) and European Society of Intensive Care Medicine (ESICM) 2017. Crit Care Med 45:2078-2088

14. Peeters $B$, Meersseman $P$, Vander Perre $S$, Wouters $P$, Vanmarcke $D$, Langouche L, Van den Berghe G (2018) The HPA-axis responses to prolonged critical illness: when do these normalize again, if at all?. Poster presented at the Annual Meeting of the Endocrine Society, Chicago

15. Boonen E, Meersseman P, Vervenne H, Meyfroidt G, Guiza F, Wouters PJ, Veldhuis JD, Van den Berghe G (2014) Reduced nocturnal ACTH-driven cortisol secretion during critical illness. Am J Physiol Endocrinol Metab 306:E883-E892

16. Vanhorebeek I, Peeters RP, Vander Perre S, Jans I, Wouters PJ, Skogstrand K, Hansen TK, Bouillon R, Van den Berghe G (2006) Cortisol response to critical illness: effect of intensive insulin therapy. J Clin Endocrinol Metab 91:3803-3813

17. Boonen $E$, Langouche L, Janssens $T$, Meersseman P, Vervenne H, De Samblanx E, Pironet Z, Van Dijck L, Vander Perre S, Derese I, Van den Berghe G (2014) Impact of duration of critical illness on the adrenal glands of human intensive care patients. J Clin Endocrinol Metab 99:4214-4222

18. Deutschman CS, Raj NR, McGuire EO, Kelz MB (2013) Orexinergic activity modulates altered vital signs and pituitary hormone secretion in experimental sepsis. Crit Care Med 41:e368-e375

19. Briegel J, Forst H, Haller M, Schelling G, Kilger E, Kuprat G, Hemmer B, Hummel T, Lenhart A, Heyduck M, Stoll C, Peter K (1999) Stress doses of hydrocortisone reverse hyperdynamic septic shock: a prospective, randomized, double-blind, single-center study. Crit Care Med 27:723-732

20. Annane D, Sebille V, Charpentier C, Bollaert PE, Francois B, Korach JM, Capellier G, Cohen Y, Azoulay E, Troche G, Chaumet-Riffaud P, Bellissant E (2002) Effect of treatment with low doses of hydrocortisone and fludrocortisone on mortality in patients with septic shock. JAMA 288:862-871

21. Sprung CL, Annane D, Keh D, Moreno R, Singer M, Freivogel K, Weiss YG, Benbenishty J, Kalenka A, Forst H, Laterre PF, Reinhart K, Cuthbertson BH, Payen D, Briegel J (2008) Hydrocortisone therapy for patients with septic shock. N Engl J Med 358:111-124

22. Annane D, Bellissant E, Bollaert PE, Briegel J, Confalonieri M, De Gaudio R, Keh D, Kupfer Y, Oppert M, Meduri GU (2009) Corticosteroids in the treatment of severe sepsis and septic shock in adults: a systematic review. JAMA 301:2362-2375

23. Blum CA, Nigro N, Briel M, Schuetz P, Ullmer E, Suter-Widmer I, Winzeler B, Bingisser R, Elsaesser H, Drozdov D, Arici B, Urwyler SA, Refardt J, Tarr P, Wirz S, Thomann R, Baumgartner C, Duplain H, Burki D, Zimmerli W, Rodondi N, Mueller B, Christ-Crain M (2015) Adjunct prednisone therapy for patients with community-acquired pneumonia: a multicentre, double-blind, randomised, placebo-controlled trial. Lancet 385:1511-1518

24. Meduri GU, Bridges L, Shih MC, Marik PE, Siemieniuk RA, Kocak M (2016) Prolonged glucocorticoid treatment is associated with improved ARDS outcomes: analysis of individual patients' data from four randomized trials and trial-level meta-analysis of the updated literature. Intensive Care Med 42:829-840

25. Venkatesh B, Finfer S, Cohen J, Rajbhandari D, Arabi Y, Bellomo R, Billot L, Correa M, Glass P, Harward M, Joyce C, Li Q, McArthur C, Perner A, Rhodes A, Thompson K, Webb S, Myburgh J, ADRENAL Trial Investigators, Australian-New Zealand Intensive Care Society Clinical Trials Group (2018) Adjunctive glucocorticoid therapy in patients with septic shock. N Engl J Med 378:797-808

26. Annane D, Renault A, Brun-Buisson C, Megarbane B, Quenot JP, Siami S, Cariou A, Forceville X, Schwebel C, Martin C, Timsit JF, Misset B, Ali Benali M, Colin G, Souweine B, Asehnoune K, Mercier E, Chimot L, Charpentier C, Francois B, Boulain T, Petitpas F, Constantin JM, Dhonneur G, Baudin F, Combes A, Bohe J, Loriferne JF, Amathieu R, Cook F, Slama M, Leroy O, Capellier G, Dargent A, Hissem T, Maxime V, Bellissant E, CRICS-TRIGGERSEP Network (2018) Hydrocortisone plus fludrocortisone for adults with septic shock. N Engl J Med 378:809-818

27. Gibbison B (2018) Diagnosing adrenal insufficiency in critical illness: time to go back to the start. Resuscitation 129:A11-A12

28. Knaus WA, Draper EA, Wagner DP, Zimmerman JE (1985) APACHE II: a severity of disease classification system. Crit Care Med 13:818-829

29. Bone RC, Balk RA, Cerra FB, Dellinger RP, Fein AM, Knaus WA, Schein RM, Sibbald WJ (1992) Definitions for sepsis and organ failure and guidelines for the use of innovative therapies in sepsis. The ACCP/SCCM Consensus Conference Committee. American College of Chest Physicians/Society of Critical Care Medicine. Chest 101:1644-1655

30. Singer M, Deutschman CS, Seymour CW, Shankar-Hari M, Annane D, Bauer M, Bellomo R, Bernard GR, Chiche JD, Coopersmith CM, Hotchkiss RS, Levy MM, Marshall JC, Martin GS, Opal SM, Rubenfeld GD, van der Poll T, Vincent JL, Angus DC (2016) The third international consensus definitions for sepsis and septic shock (sepsis-3). JAMA 315:801-810 